\title{
Contesting Human Rights through Institutional Reform: The Case of the UK Equality and Human Rights Commission
}

\author{
Katherine Tonkiss \\ Lecturer in Sociology \\ School of Languages and Social Sciences \\ Aston University \\ Birmingham \\ B4 7ET \\ 01212044416 \\ k.tonkiss@aston.ac.uk
}

Word count: 9366

Acknowledgments: This research was supported by the Economic and Social Research Council (ES/J010553/1). The author is additionally grateful to Chris Skelcher for helpful comments on previous drafts.

Biographical note: Katherine Tonkiss is a Lecturer in Sociology and Policy at Aston University. Prior to this she worked as a Research Fellow at the University of Birmingham on 'Shrinking the State', an ESRC-funded research project examining the reform of arm's length bodies in the UK. 


\title{
Contesting Human Rights through Institutional Reform: The Case of the UK Equality and Human Rights Commission
}

\begin{abstract}
This paper presents a case study of the recent reform of the UK Equalities and Human Rights Commission, to address a critical gap in the literature on national human rights institutions (NHRIs) concerning the power of governments to exert control over these institutions through reform processes. Through this analysis, the paper demonstrates, firstly, that NHRIs are affected by contextual factors not only related to the popularity of the human rights agenda but also to wider policy agendas which impact on their status and functions; and secondly, that attempts by government to exert more administrative control can be significantly problematic for the operational independence of NHRIs.
\end{abstract}

Keywords: NHRI; Equality and Human Rights Commission; institutional reform; United Nations; independence

\section{Introduction}

National Human Rights Institutions (NHRIs) locate the promotion and protection of international human rights norms within the existing state system. Their institutional form and duties are shaped by the Paris Principles which were agreed by the United Nations Human Rights Commission in 1992 and set out the key criteria that NHRIs must meet to receive UN accreditation. Though the creation of NHRIs is therefore a relatively recent development in the evolution of the post-war international human rights movement, ${ }^{1}$ they have become very widespread - in 2014, 106 NHRIs existed across Africa, Asia, Australasia, Europe and North and South America. ${ }^{2}$ 
NHRIs, it has been noted, occupy a 'unique' and somewhat awkward position within the state, both independent from national government, civil society and non-governmental organisations (NGOs) but also accountable to them for their performance and effective governance. ${ }^{3}$ Accountability relationships with government are particularly challenging: NHRIs are funded through public expenditure from the state in which they are located, and therefore while one of their critical roles is to hold governments to account on human rights, those same governments hold NHRIs to account for the efficient use of public funds. These relationships are also complex. Anne Smith has identified multiple types of independence relating to different parts of the institutional structures of NHRIs, including operational, financial, recruitment and pluralism of membership. ${ }^{4}$ This means that NHRIs can experience different levels of independence for different parts of their organisation, with operational independence normally greater than administrative independence.

While noting that NHRIs are not shielded from the political context in which they operate, ${ }^{5}$ one aspect of the complex relationship with government that has not been explored is the power of government to reform NHRIs and in doing so change the balance between independence and accountability. By virtue of their position below the political structures of the nation-state system, the existence of an NHRI rests somewhat precariously on its public and political support. While the government of an unpopular NHRI may be loathed to abolish the institution in order to protect its international human rights reputation, it does have the option to instigate substantial reforms which can decrease the independence of an NHRI and marginalise human rights protections. There are also questions over what constitutes appropriate reform. Government has a legitimate concern in ensuring that NHRIs are accountable for spending public money 
and may engage in the reform of an institution to ensure that this accountability is in place, but the challenge is ensuring that this reform concerns imposing legitimate control and does not stray into illegitimate interference which might compromise the ability of the NHRIs to protect and promote human rights.

This paper presents a detailed case study of the reform of the UK Equality and Human Rights Commission (EHRC), to examine how a government asserts its authority over an NHRI through institutional reform and the challenges this raises for finding an appropriate balance between independence and accountability. The EHRC opened for business in 2007 and was tasked with an ambitious vision for the protection and promotion of human rights through the creation of a rich human rights culture. Yet, by 2014 (and just seven years later), many of its responsibilities had been repealed and its independence from government had been much reduced. By focusing on institutional reform as a form of contestation over the value and reach of human rights, the paper adds a new perspective to the literature on the institutional form and governance of NHRIs.

The paper draws on a large documentary data archive to complete the analysis of this case, which includes EHRC publications, publications of the Joint Committee on Human Rights $^{6}$ (JCHR), consultation and strategy documents related to the reform of the EHRC, parliamentary committee reports and publicly available correspondence between senior politicians and EHRC leadership. This documentary analysis is supplemented with data from five open-ended, semi-structured interviews with former and current members of EHRC management and with civil servants tasked with overseeing the relationship between the government and the EHRC. Each of these interviews lasted for one hour, and was transcribed and coded for common themes. 
The paper shows that internal governance problems which had plagued the EHRC since its set-up raised a legitimate need for reform in order to ensure effective accountability for public expenditure. This, combined with growing hostility towards the human rights agenda and other intersecting policy agendas associated with austerity, created a political impetus for reform. As a result, government engaged in a radical programme of reform with significant implications for the EHRC, which affected not only its accountability for spending public money but also the wider independence of its operational functions. Yet despite the reform compromising this operational independence, the institution has remained in broad compliance with the Paris Principles and there has been relatively little intervention from the UN.

The paper provides insights from these findings for the independence-accountability dilemma facing NHRIs. Specifically, it argues that intersecting and often only tangentially related policy agendas affect the independence of NHRIs just as much as governance problems, and that administrative and operational independence are not neatly separable, with the limitation of administrative independence producing consequences for the day-to-day operation of NHRIs. This in itself highlights the challenge of building NHRIs which strike an appropriate balance between accountability for public spending and operational independence, and as a result raises wider concerns about the effectiveness of the international system in encouraging improvement in human rights protections and the building of rights-based societies.

\section{National Human Rights Institutions}

While the UN has, since its inception in 1945, led the way in promoting respect for human rights internationally, '[t]he central responsibility for protecting human rights rests with Governments'. ${ }^{7}$ On ratifying a treaty, a state assumes responsibility to 
respect, protect and fulfil the rights contained within that treaty (beyond simply preventing human rights abuses), and ensuring that these rights are institutionalised into the state's legal system. NHRIs are a vehicle for meeting these obligations.

The possibility of national level enforcement bodies was considered by the UN as far back as 1946 and discussions continued throughout the next four decades. ${ }^{8}$ Yet it was only in the 1990s, when NHRIs were placed on a more formal international footing, that they began to proliferate internationally. The formation of the 'Paris Principles' provided the formal footing for NHRIs when they were ratified by the UN General Assembly in 1993. These principles provided guidance on the competences and responsibilities of NHRIs, their guarantees of independence and their methods of operation. ${ }^{9}$ The principles include, among others, recommendations that NHRIs must have as broad a mandate as possible to protect and promote human rights, should be independent from government and provided with sufficient funding to exercise their functions on an independent basis, and should have extensive pluralism in their membership. While broad enough to permit institutional diversity in different national settings, these principles offer a cohesive set of standards by which to evaluate the performance of NHRIs and institutions are rated as A, B or C according to the level of their compliance with these principles. Attaining A status has therefore become an issue of international reputation, denoting the highest level of human rights accreditation.

The proliferation of NHRIs since the early 1990s has occurred across a range of different types of political system and across diverse geographical regions as a result of a widespread desire to gain the recognition of international audiences for a strong human rights record. ${ }^{10}$ The UN has also continued to play a central role in encouraging the creation of NHRIs and the development of transnational strategic relationships 
between them. ${ }^{11}$ As of 2014 , there were 106 NHRIs worldwide and of these 71 were A status (fully compliant with the Paris Principles), 25 were B status (partially compliant) and ten were $\mathrm{C}$ status (not compliant). ${ }^{12}$

The proliferation of NHRIs worldwide has been accompanied by considerable academic attention focused on these emerging institutions. ${ }^{13}$ The issue garnering the most attention has been the independence of NHRIs, given their accountability to government for the use of public funds. ${ }^{14}$ This independence-accountability tension is inherent in the institutional form of NHRIs. Human rights apply universally, attributed to individuals in virtue of their humanity; yet, the extent to which they are currently recognised is at the discretion of states themselves and the UN's role is one of 'achieving international cooperation' rather than enforcement. ${ }^{15}$ As a result, NHRIs are funded from public resources allocated to them by government and, while an appropriate level of operational independence is critical to maintaining an A status NHRI, administrative accountability to government for the use of public money and for efficiency of performance is also critical.

The tension is also inherent to the institutional reform of NHRIs because they belong to a class of organisations often referred to as 'arm's length', in that they are publicly funded bodies carrying out public functions but with some degree of independence from government. ${ }^{16}$ The arm's length governance literature has mirrored the focus on the independence-accountability tension, ${ }^{17}$ but has also examined the reform of arm's length bodies as the assertion of government authority over institutions due to concerns regarding performance or efficiency, or because of wider political agendas such as the diminishing popularity of arm's length bodies and a desire for greater accountability in public life. ${ }^{18}$ This literature also suggests that moments of institutional 
reform are a form of contestation over the value of the institution and its governance. ${ }^{19}$ In relation to NHRIs, however, we know comparatively little about the factors which drive reform or about the consequences of these reforms for the protection and promotion of human rights. It is to the task of filling this gap that this paper now turns, through a case study of the UK Equality and Human Rights Commission (EHRC).

\section{The Equality and Human Rights Commission}

The EHRC was established as an independent statutory body by Parliament under the Equality Act 2006. Its remit covers England, Scotland and Wales, but not Northern Ireland where there is a separate statutory body for equality and human rights. Human rights were largely an 'after-thought' in its creation. ${ }^{20}$ Although the need for a stronger commitment to human rights in the UK was noted in the early 1990s, the matter did not return to the table until 1996 when the Human Rights Act began to be drafted, but even this Act did not include any provisions for a UN-accredited NHRI. ${ }^{21}$ Rather, the key motivation for the creation of the EHRC was the introduction of new European Council directives on employment and race, which sought to prevent discrimination on grounds of racial or ethnic origin, religion or belief, age or sexual orientation. ${ }^{22}$ This led to the passage of the Equality Act in 2006 which brought all existing equality legislation into one Act and ensured compliance with the new directives. The Act also created the EHRC as a single body tasked with implementing the provisions of the legislation across all seven criteria recognised by the European directives. The EHRC replaced three preexisting equality bodies (the Commission for Racial Equality, the Disability Rights Commission and the Equal Opportunities Commission); these bodies were initially hostile to the possibility of merger but eventually supported the move on the grounds that it could allow them to more effectively promote equality and non-discrimination. ${ }^{23}$ 
It was the Joint Committee on Human Rights (JCHR) which made the core case for this new commission to include human rights responsibilities. It was the judgment of the JCHR that the Human Rights Act was insufficient, and that the legal process should be a last resort in protecting rights. Rather, a new institution could raise awareness of the need to promote human rights in public authorities and could communicate with and guide the public in asserting those rights. ${ }^{24}$ It was also the view of the Committee that the right to equal treatment should be considered a human right and therefore equality was thought of as compatible with human rights - and, therefore, there should be a single equality and human rights body. ${ }^{25}$ This approach is in keeping with the Paris Principles, which state that NHRIs should publicise human rights alongside 'efforts to combat all forms of discrimination'.26 The independence of the body would be critical however, as the Committee noted:

In our view, a human rights commission should be regarded as part of the mechanism for protecting the rights of the individual against the misuse of the power of the state - it would have failed were it to be seen as an instrument of government. ${ }^{27}$

The government announced that it would proceed with the creation of the EHRC, combining equality and human rights duties, in October 2003. The pre-existing equality bodies were less supportive of the idea of combining equality and human rights, but did come to support the move on the basis that the human rights functions would provide additional instruments for pursuing equality objectives. The JCHR recommended that the new body should have as wide a remit as possible, with the aim of achieving strategic change through promotion, advice, spreading best practice and raising public awareness. From the outset, the intention was to build an institution which was capable 
of creating a rights-based society with a robust human rights culture, and therefore the promotion of human rights was thought of in its most expansive sense. ${ }^{28}$

This vision of a rights-based society was embodied in the core 'general duty' of the EHRC:

The Commission shall exercise its functions... with a view to encouraging and supporting the development of a society in which -

(a) people's ability to achieve their potential is not limited by prejudice or discrimination,

(b) there is respect for and protection of each individual's human rights,

(c) there is respect for the dignity and worth of each individual,

(d) each individual has an opportunity to participate in society, and

(e) there is mutual respect between groups based on understanding and valuing of diversity and on shared respect for equality and human rights. ${ }^{29}$

In addition, the Equality Act provided the EHRC with five core powers:

1. Monitoring the law and providing legal assistance

2. Providing information and advice

3. Conducting inquiries and judicial reviews

4. Providing and conciliation service

5. Allocating grants

The EHRC was classified as a non-departmental public body (NDPB), which is the dominant form of arm's length body in the UK. The choice of the NDPB model for the EHRC was a contentious one, with the JCHR keen to explore alternative options which could maximise the independence of the new commission, ${ }^{30}$ but the government 
viewing the NDPB model - which had been the classification of the preceding bodies as preferable. As a result of this NDPB status, the EHRC is allocated funding by government, is sponsored by a government department (the Government Equalities Office - GEO), and is accountable to Parliament through the Equalities Minister. ${ }^{31}$ The Commission was originally set up with a board of 10-15 Commissioners who are appointed by the minister, and who may be dismissed by the minister should s/he judge them to be unfit or unwilling to perform their duties. ${ }^{32}$

\section{The Story of EHRC Reform}

The EHRC was launched as planned on $1^{\text {st }}$ October 2007, and became the UK's leading authority on equality and human rights issues. It raised awareness of human rights and discrimination issues, for example through the publication of reports such as How Fair is Britain, ${ }^{33}$ a report which analysed the progress made in the UK against key equality and human rights indicators. It conducted statutory inquiries and assessments, and intervened on numerous important human rights cases, such as on the rights of gay and lesbian asylum seekers and on the rights of disabled people. It also provided advice to government on the equality and human rights implications of key policy issues such as the use of body scanners in airport security, holding the DNA of those found innocent of a crime on a central database, and using information gained through torture. ${ }^{34}$

However, the Commission suffered significant problems in its governance and performance from the start. The Public Accounts Committee, a committee of the House of Commons, reported in 2010 that there had been serious errors in setting up the EHRC, which had been further problematized by having three changes of sponsor department in the three months immediately preceding its launch. While first it was sponsored by the Department for Communities and Local Government, it was then 
transferred to GEO on that department's creation, and then moved with GEO when that department was itself subsumed to become a part of the Home Office. ${ }^{35}$ The Commission accepted that it was not ready for business when it opened in 2007, something the Public Accounts Committee attributed to a delay in appointing key staff. The set-up of the institution was found to be flawed and inefficient (costing $£ 38.8 \mathrm{~m}$ ), with shortcomings in the leadership of the board and also mistakes by the EHRC transition team which did not effectively organise the transfer of staff. This left gaps in knowledge and expertise which meant that former employees had to be brought back.

The reappointment of staff that had been given severance packages, a process which cost the Commission over $£ 300,000$, was not subject to Treasury approval, and therefore value-for-money concerns were raised. As a result, EHRC expenditure was deemed irregular by the Comptroller and Auditor General, who gave a qualified opinion on the EHRC accounts in the period 2006-08. Similarly severe financial problems continued after the statement of this qualified opinion, and the EHRC also lacked appropriate leadership at this time - it had not had a Chief Executive since May 2009.36

Furthermore, former commissioners who had resigned in 2009 raised concerns about how the chair of the time had led the agency. The contended that the board was not functioning as a corporate body, commissioners felt intimidated to hold the chair to account, and there was a perceived conflict of interest with the chair's involvement in a private consultancy firm (a controlling share which was subsequently relinquished), although these accounts have been contested by continuing commissioners. There were also concerns about how the former chair was reappointed in 2009 by the then Labour minister without open competition, driving concerns about his political independence. ${ }^{37}$ 
Also in 2010, the JCHR reported that 'the EHRC is not fulfilling the human rights mandate set out in the 2006 Act', and expressed a concern as to 'whether the EHRC is doing enough to devise and disseminate a culture of respect for human rights in public authorities'. ${ }^{38}$ The Committee felt that the Commission was not addressing human rights in a systematic way, and the human rights strategy which the EHRC had created was judged to be too vague and in need of more clear relation to the institution's objectives. As Human Rights Minister Michael Wills MP commented to the inquiry, 'I do not think [the EHRC] are doing enough to promote human rights and the Human Rights Act' ${ }^{39}$

The governance problems experienced by the EHRC were a driving force in the decision of the subsequent Conservative-Liberal Democrat government, which came to power in 2010, to reform the institution. This is perhaps unsurprising given the severity of its financial problems. The EHRC received $68 \%$ of the total central government equalities budget and therefore government was heavily invested in ensuring that it could deliver value for money and performance. ${ }^{40}$ Yet there were a number of other political agendas which converged on the reform of the EHRC - specifically, an overarching austerity agenda, an anti-NDPB agenda and an anti-human rights agenda. These agendas help to fully explain the way in which the EHRC was reformed, beyond only improving financial accountability mechanisms.

Having come to power on a wave of public support for austerity policies, government was keen to reform the EHRC in order to increase efficiency and reduce waste. The austerity agenda associated with the Conservative-Liberal Democrat government of the time is as such an overarching and broad narrative within which the reform of the EHRC was situated, and for the EHRC this meant delivering improvements in its 
functions in light of criticism while also spending far less money, as one interviewee noted 'it was accepted that the austerity argument of a shrinking public purse [was] not one we could push back on'. ${ }^{41}$

The implications of the austerity agenda for the EHRC were most clearly expressed through a secondary policy agenda, the anti-NDPB agenda, which combined these austerity-related concerns over increasing public sector efficiency with a perceived need to reform the EHRC's institutional form. The Coalition Government swiftly set out its intentions to conduct a review of non-departmental public bodies in 2010, and subsequently set about reducing the number of NDPBs by 285 as the result of abolitions, mergers and transfers into the private and not-for-profit sectors. ${ }^{42}$ As an NDPB itself, the EHRC was not shielded from the agenda. This contrasted with the enthusiasm with which the Labour government had embraced the NDPB organisational form for the EHRC at the time of its creation, perhaps due to the fact that this had been the form of organisation used by the pre-existing equality bodies and it had not caused any significant problems. However, in a letter to the chair of the JCHR, Theresa May MP (the Home Secretary) wrote of the NDPB review:

The review's aims were to increase accountability for actions carried out on behalf of the state, to cut out duplication of activity, and to discontinue activities which are no longer necessary. The future of the [EHRC] was considered as part of this review. 43

The reform of the EHRC was therefore framed in relation to a focus on increasing accountability and cutting waste in public life, the core aims of the wider Public Bodies Reform Programme. ${ }^{44}$ It was noted that: 
The Government remains of the view that there is a clear need for an independent equality regulator and national human rights institution. However, whilst the Commission has carried out some important work and has deepened our knowledge and understanding of issues around equality and human rights, its overall performance to date has been weak. It has struggled to deliver against its policy remit, for instance attracting criticism on its... failure to integrate human rights into its work. At the same time it has not been able to demonstrate that it is delivering value for taxpayers' money resulting in the qualification of its first two sets of accounts. ${ }^{45}$

The EHRC was, therefore, included in the Public Bodies Act (2012), which provided the government with statutory authority to engage in its reform. The government was concerned that 'the EHRC should be retained but substantially reformed to focus it on areas where it can add value, to increase its accountability to Government, Parliament and the public and to improve its effectiveness and value for money'. ${ }^{46}$ The decision was a contentious one. Early Day Motions were tabled by Caroline Lucas MP, John MacDonnell MP and Sandra Osbourne MP in support of the EHRC, and Baroness Thornton tabled an amendment to remove the EHRC from the Public Bodies Act when it was debated in the Lords. She argued that 'the fact the organisation established to safeguard equality and human rights, the independence of which is vital, should be subject to a procedure which may threaten that independence to act on behalf of those discriminated against, including against the state, has to raise questions' ${ }^{47}$ However, government was not moved to alter its plans and the reform of the EHRC proceeded.

A further set of reasons for the government's desire to push through the reform of the EHRC in the face of this opposition is associated with an anti-human rights agenda 
which is apparent from the analysis, with interviewees expressing a view that the government wanted to 'send a political signal'48 on human rights through the marginalisation of the body. The EHRC had long been operating in a 'largely unfavourable public climate towards human rights', ${ }^{49}$ with human rights often seen as driving unnecessary 'political correctness', wasting public money on bureaucratic and legalistic processes seen to contravene common sense. Common headlines from populist tabloid newspaper the Daily Mail, for example, would claim that these human rights rulings are bonkers' and 'political correctness continues to stifle debate on multiculturalism'.50 Political support for human rights had also been weakened by the security agenda which developed post $9 / 11$ and led to the development of controversial policies seen to contravene the right to liberty and security - and an issue on which the EHRC was vocal. 51

When the Coalition Government came to power in May 2010, it became clear that the typically Conservative antipathy towards equality and human rights law was likely to have implications for the Human Rights Act and for the EHRC. Indeed, in the six months prior to the 2010 general election, the EHRC was the subject of many parliamentary questions from Conservative MPs, and while many of these focused on its financial performance, many more challenged the EHRC on operational matters. In total, twelve parliamentary questions on subjects related to the operations of the EHRC were tabled in this six month period, for example on the activities of the EHRC in guiding local authorities on appointments, on their work with traveller communities, and on their use of public relations companies. ${ }^{52}$ Furthermore, two of the questions related to the way in which the EHRC sought to influence parliamentarians concerning specific particular policy decisions, including on giving convicted prisoners the right to vote. At the same 
time, the chair of the EHRC was referred by MPs to the Privileges Committees of both Houses over concerns that his communication with members of the Joint Committee of Human Rights amounted to inappropriate parliamentary conduct. 53

In addition to this concern for the operations of the EHRC, the organisation was itself representative of the Human Rights Act which the Conservative party had committed to abolishing in their 2010 manifesto. ${ }^{54}$ Indeed, Prime Minister David Cameron even stated that his party would have abolished the Act if it had not been for their Liberal Democrat coalition partners, and has committed to doing so since his party won a full majority at the 2015 general election. ${ }^{55}$ Due to the different viewpoints within the Coalition at the time, the Government was not able to implement any reform of the Human Rights Act ${ }^{56}$ but institutional reform of the EHRC was far more straightforward, as one interviewee described, You can't “you've got to get rid of [the Human Rights Act]”... What you can do is... make most of it difficult to enforce by reducing the power and potency of the enforcement agency, ${ }^{57}$ and another commented:

It was because we were almost, as a guardian of the Human Rights Act in the UK, it was quite clear that, because it was quite a hostile take on the Act... it was clear that our functioning and our mission would also become under attack... the rationalisation [was] very much as a means to shrink our radius of action and therefore, less people would [mean] less intrusion and therefore, less us talking back to government about the Human Rights Act. ${ }^{58}$

Government's proposals for the reform of the EHRC were set out in the Building a Fairer Britain white paper. ${ }^{59}$ The proposals drew on 993 responses to consultation on the future of the EHRC, including 224 organisations and 769 individuals. Most of the organisations were those representing the kinds of groups whose interests were 
typically protected by the EHRC. Over half of the responses from individuals were calling for the abolition of the EHRC, while others focused on poor leadership and management. Most were unhappy with EHRC performance.

The EHRC itself responded to the consultation, and in its response highlighted how the Commission had been making progress towards better defining and delivering core functions as an effective outcome-focused regulator, non-partisan, evidence-led champion of equality and human rights, and an expert leader for both practitioners and wider society.60 With reference to negative public opinion about equality and human rights, the response noted: 'In order to see beyond the popular and mistaken conception of equality and human rights as being about political correctness, tick boxes and red tape, the Commission needs to have the capacity to operate with a clear set of universal values that will "speak" to every section of society". ${ }^{61}$

The Consultation responses were considered alongside views expressed through the Government's Red Tape Challenge Spotlight on Equalities in June 2011, a policy allied with the austerity-motivated focus on efficiency in public expenditure, and also in light of more positive outputs from the EHRC such as its first satisfactory set of accounts, the prompt publication of a new strategic plan, and a 75\% reduction in dependence on interim staff. However, there were still concerns about the quality and timeliness of the Commission's work and the extent to which its activities were genuinely adding value.

The government wanted the EHRC to be 'a national expert on equality and human rights issues, and a strategic enforcer of the law and guardian of legal rights'.62 This meant a far more streamlined, minimal and legalistic view of the EHRC's role, in comparison to early ambitions for the institution as leading the creating of a human rights culture and rights-based society through a wide range of activities. Plans were made to repeal the 
EHRC's general duty, which was seen as lacking specific legal purpose and clarity. This proposal was dropped in April 2013 owing to widespread opposition from the Lords, but the EHRC's duty to monitor progress against this general duty was abolished, and rather the EHRC must monitor progress against its more narrowly and legalistically defined mandate for human rights. The EHRC's good relations duty was also repealed because its most valuable work was judged to be carried out under existing equality and human rights functions, and the EHRC was also to stop non-core activities such as its helpline and conciliation service on the basis of concerns about reach, effectiveness and value-for-money, with services instead commissioned from the private sector or civil society. 63

In addition, the EHRC was also to improve its financial and operational performance by implementing a new framework document giving detailed instructions on its governance and including much tighter financial control powers for the government, and conducting a zero-based budget review to explore the resources needed to underpin the new legalistic and strategic focus of the agency. ${ }^{64}$ EHRC leadership and governance would also be strengthened through the introduction of a smaller board and a new chair.

In summary, the reform of the EHRC can be explained with reference to a perceived need to increase governmental control in order to reduce inefficiency at a time of public sector austerity and spending cuts, and from a desire to marginalise the organisation as the result of an anti-human rights agenda. While the context of austerity would likely have meant that the institution would have been subject to spending cuts regardless of its popularity, the decision for more wide-ranging reform is rooted in a combination of these wider policy agendas. As such, in the case of the EHRC it is apparent that while 
independence has been lost as a result of poor governance mechanisms, the story of reform also points to the importance of context to the independence of NHRIs and their functions. The EHRC was unpopular due to a variety of intersecting policy agendas, and as a result political forces converged on reform. ${ }^{65}$ The result of institutional reform was far from simply to limit administrative independence as a result of poor internal governance; rather, it is apparent that the operational activities of the EHRC were significantly affected by reform. This led to a fundamental shift in the purpose of the EHRC from creating and maintaining a rich and expansive human rights culture to meeting narrowly defined legal obligations.

\section{Implications for Independence}

Many of the perceived problems with the EHRC which drove this programme of reforms had their roots in the independence-accountability tension facing NHRIS which are at once independent human rights regulators and state-sponsored bodies with financial accountability to a national government. There was a view that the EHRC had assumed too much independence and as a result had failed to deliver good governance and the efficient use of public funds. As one interviewee noted, 'it was partly out of control because it regarded itself as a uniquely independent body that didn't take instructions from anybody'.66

The consequence of reform for the independence of the EHRC have been significant. To start, Government Equalities Office as the sponsoring department has developed open lines of communication with the EHRC in order to 'get a much better view of what they're up to on a month by month basis'. ${ }^{67}$ The EHRC's framework document now sets out its governance arrangements, financial controls and requirements for reporting to GEO in extensive detail, and incorporates specific provisions for bimonthly ministerial 
meetings as well. For GEO and the government, such mechanisms are seen as critical in ensuring the good governance of the EHRC and thought of as restricted to administrative rather than operation control; however, for the Commission itself it can appear as unnecessary with the potential to compromise independence. One interviewee, for example, described GEO as 'volunteering to be the schoolyard bully' and coming 'to a point of controlling the minutia of the way we spent our budget... it was becoming quite invasive' ${ }^{68}$

Financial control has been a key issue in this contestation over the independence of the Commission. While this control is embedded in the framework document of the EHRC, ${ }^{69}$ it also results from a framework of controls which has been applied across government and government-sponsored public bodies since 2010, when the incoming government sought to significantly control and reduce public sector spending. As a result of institutional form, then, the EHRC has fallen under the remit of these controls. They impose limits on expenditure across a range of administrative areas including advertising and marketing, recruitment, information technology and consultancy, where spending above the approved limit requires departmental, Cabinet Office or Treasury approval depending on the amount of expenditure involved. ${ }^{70}$

For the EHRC, this spending controls framework has represented a significant limitation on financial independence, and has led to some controversies which suggest that controls on financial independence can themselves compromise operational independence. For example, in 2010 the Commission conducted an inquiry into the human rights of older people receiving in-home care ${ }^{71}$ and this led to the production of a second publication aimed at ensuring that those older people understood their human rights. ${ }^{72}$ However, as a result of limits on expenditure, the government proposed that 
the publication should be online only. The EHRC had to protest to the government that it was essential for the publication to be produced in print in order for it to reach its audience and eventually an agreement to publish in print format as well as online was reached. ${ }^{73}$ However, for the EHRC this is a demonstration of the ability of these controls on expenditure to impact on operational independence - the things that the EHRC is doing on a day-to-day basis. Similar concerns were raised with regards to recruitment:

If I want to hire a barrister to give me an opinion about a human rights case, particularly for example if it's against the government, Treasury and Cabinet Office will require that I submit a business case for spending $£ 10,000$. And part of their judgment will be, "is this a sensible thing on which to challenge the government?"74

In this example, the interviewee is describing their fear that they would have to have a spending decision to hire a lawyer to directly challenge government policy signed off by that same government, again an apparently administrative form of financial control with significant implications for operational independence.

The government has also taken steps to replace senior leadership appointments at the Commission, in addition to the chair. The emphasis has been on replacing previous appointees who tended to have particular experience with groups facing discrimination and with experience of campaigning and lobbying on the part of such groups, with those who could demonstrate expertise rather than direct experience. This included appointing ex-civil servants to senior positions in finance, corporate services and legal services, and appointing Baroness O’Neill, a leading academic in the field of human rights, as chair. This was viewed positively by interviewees from GEO, for example: 
...legal specialists, a business voice has been introduced this sort of thing. It's not just a direct feed through from the charitable sector and lobbies into the Commission... The effect has been substantial because you can actually... these people actually know how Government works. ${ }^{75}$

Yet, this in itself represents a form of administrative control over the EHRC which has the potential to compromise operational independence, as the view of the Government that leadership and board members should combine expertise in equality and human rights issues with experience of working with government, rather than working with NGOs or civil society, is institutionalised as a more positive but potentially less challenging relationship with the Government.

Most recently, concerns for the independence of the EHRC have been raised with regards to the Deregulation Bill, which entered the House of Commons on 23 ${ }^{\text {rd }}$ January 2014. This Bill is intended to reduce burdens on businesses, organisations and individuals stemming from legislation, and includes a 'growth duty' on non-economic regulators (of which the EHRC is one) to have due regard to economic growth when carrying out their regulatory functions. ${ }^{76}$ The EHRC expressed the concern that this would potentially compromise their independence on the basis that it conflicted with their ability to complete their equality and human rights duties and this was supported by an amendment tabled in the House of Lords by Lord McNally at the eighth sitting of the Committee stage, who argued that:

...subjecting the Commission to the growth duty presents a real risk of the UN NHRI A status being downgraded for non-compliance with the Paris Principles because the growth duty is or could be perceived to be a constraint on the independent exercise of the body's core functions. ${ }^{77}$ 
While the government has suggested that it intends to make special provisions for the EHRC to avoid such independence problems, Lord McNally's proposal was to name the EHRC as exempt in the Bill itself. This was not supported in the Lords.

There is persistent contestation over the problems of independence and accountability experienced in the governance of the EHRC, but the configuration of an anti-human rights agenda with a range of other convergent policy agendas which support its marginalisation is likely to mean that its status remains the same. The Joint Committee on Human Rights has expressed concerns over the implications of the reforms undertaken for the A status rating of the EHRC, and these have also been echoed by the UN in a letter to Theresa May in June 2012. This letter called on the government to 'review some of the proposals with a view to preserving the EHRC's independence and to ensuring its continued compliance with the Paris Principles relating to the status of national institutions', and, in relation to the changes in skills requirements for leaders of the organisation, called on the government to have due regard to the Paris Principles which require 'pluralist representation of the social forces involved in the promotion and protection of human rights'. ${ }^{78}$ The ICC also vocalised concerns that while considered individually the reforms would not impact on the A status of the EHRC, as a whole 'the package of proposals clearly constitutes a diminution of the EHRC's role and responsibilities', noting particular concerns about the budget cuts faced by the EHRC, the framework document, and that the reforms could 'contradict the Government's stated recognition of the importance of the EHRC to be free from undue influence in the exercise of its functions'. ${ }^{79}$ However, the ICC has no intention of reviewing the EHRC's accreditation in its current plans which run to the end of 2017. 
The literature on the independence-accountability tension affecting NHRIs correctly identifies administrative and operational forms of independence, and emphasises that importance of defining between the two in order to retain an appropriately independent status while still being accountable for the use of public funds. However, the case of the EHRC has shown a number of ways in which administrative and operational forms of control are inter-related, which means that in having administrative control, a government can affect change to operational matters. This dynamic was exposed in the reform of the EHRC, and is critically important to understanding the position of NHRIs in relation to national governments.

\section{Conclusion: Institutionalising Human Rights}

This paper aimed to explore a case of a government instigating the reform of an NHRI, to provide insights for debates over how human rights should be institutionalised within the existing state system. It told the story of the reform of the UK Equality and Human Rights Commission, which demonstrated how the remit of the EHRC was fundamentally changed and its independence systematically reduced.

In exploring the case of the reform of the EHRC, the paper has added another layer to a literature highlighting the problems and tensions which emerge from the position of NHRIs which are at once above and below government. The government had legitimate reasons to reform the EHRC on the basis of significant problems in its financial management which compromised its accountability for public expenditure. However, intersecting policy agendas focused on the need to cut public spending and to increase the accountability of non-departmental public bodies, as well as an anti-human rights agenda, led to far-reaching reform of the EHRC which had significant implications for its operational independence. NHRIs are built to some extent on the premise that it is 
possible to separate accountability for public funds from operational independence, but these findings suggest that the two are far less separable than may have been thought. This raises a significant challenge in finding the appropriate balance for NHRIs between legitimate accountability for spending public money, and illegitimate interference in operational matters.

The power to reform is a key way in which government is able to assert its authority over NHRIs. While international reputation can act as a coercive force to prevent abolition of the institution and its core duties - as in the case study, the EHRC was not abolished and did retain its core general duty - the case did illustrate that governments are able to significantly curtail the remits of NHRIs without concern for this reputation because these reforms to some extent fell 'under the radar' of the Paris Principles criteria. Proponents of the institutionalisation of robust human rights cultures in the existing state system may find much to be concerned about. Far from driving such an expansive notion of a rights-based society and despite early ambitions to realise this expansive view, the EHRC has been disempowered and marginalised to a more minimal legal role within seven years of its creation. This was the result of a negative climate surrounding human rights, but it was also the result of a convergence of a number of policy agendas, some of which were very remote from the work of the EHRC but nonetheless underpinned its reform as politicians worked to implement these wider agendas. This demonstrates that NHRIs do not only face the challenge of changing will towards human rights in their position below government control, but also must deal with changes in wider policy agendas which impact on their status. These findings about the EHRC fly directly in the face of the OHCHR assertion that '[i]n the past 20 years, national human rights institutions have developed into increasingly independent 
and authoritative actors actively engaging with the UN human rights mechanisms' and rather suggests that the EHRC is moving backwards from its initial aim of building an expansive notion of a rights based society. ${ }^{80}$

The paper also offers insights for debates over how human rights should be institutionalised. Despite the independence-accountability tension, generally it is thought that NHRIs offer the best way of institutionalising human rights within the existing state system. This paper, however, offers some reasons to dispute this. An institutional cosmopolitan might suppose, from these findings, that because we have duties to create just institutions, NHRIs are simply unable to instigate the kinds of radical changes that are needed within societies because they are constantly kept in line by government with the threat of reform and operational control through administrative means. Rather, we might look beyond the state to create institutions with the power to enforce human rights and be held to account outside of the states in which they operate.

The present paper does not offer the scope to consider the merits of such a cosmopolitan argument, though it is noted that it is one possible and logical outcome of the case presented. For example, one possible course of action would be to fund NHRIs through a reformed United Nations, which could then implement accountability for public expenditure beyond the state. However, given the spirit of the paper it is perhaps more sensible to offer some insights for the existing state system, even if this may be a non-ideal state of affairs. For the existing system, the paper suggests that there are shortcomings in the extent to which the Paris Principles truly encourage the development of robust rights-based societies. In the case of the EHRC, the government has been able to enact significant reforms with only very limited interference from the 
UN and no immediate threats to revoke its A status. While the government doesn't want to lose its A status for reasons of international reputation, it also has plenty of room to manoeuvre and the Paris Principles have not set the EHRC on a trajectory of improvement towards embedding a human rights culture. As one interviewee commented on the government:

They didn't even understand the Paris Principles... to the point that the GEO even wrote back to the UN saying "oh, we don't think they should have that much independence because we don't think they will do their budget really well". And it's like, how can you send a more stupid letter to the UN? ${ }^{81}$

This quote illustrates the very point that the Paris Principles are remote to national governments, and seem to carry little weight over more pressing political agendas which can significantly compromise the role, functions and independence of NHRIs - an inherent weakness evident in the Paris Principles from their inception. ${ }^{82}$

Reforming the Paris Principles to make them a) more binding and enforceable, and b) focused on driving improvement, may be an important step in developing flourishing human rights cultures. Achieving this reform in itself would of course be challenging because national governments are unlikely to want to cede greater control over human rights to a supranational institution; however, given their interest in rating their $\mathrm{A}$ status, reform is not impossible. Part of this reform could be to place a duty on government to preserve the operational independence of NHRIs by making them accountable to Parliament rather than government, as is the case for some other NHRIs such as the Scottish Human Rights Commission, so that NHRIs to some extent are able to exist independently of the policy agendas pursued by individual governments. 


\title{
Acknowledgments
}

\author{
Anonymised for peer review
}

${ }^{1}$ C. Raj Kumar, 'National Human Rights Institutions: Good Governance Perspectives on the Institutionalisation
of Human Rights', American University International Law Review 19, no.2 (2003): 260-300.
2 International Coordinating Committee on National Institutions for the Promotion and Protection of Human
Rights (ICC), 'Chart of the Status of National Institutions'
http://nhri.ohchr.org/EN/AboutUs/ICCAccreditation/Documents/Chart\%20of\%20the\%20Status\%20of\%20NHR s\%20\%2823\%20May\%202014\%29.pdf (accessed 24/6/15).

${ }^{3}$ Anne Smith, 'The Unique Position of National Human Rights Institutions: A Mixed Blessing?', Human Rights Quarterly 28, no.4 (2006): 904-946; Sarah Spencer and Colin Harvey, 'Context, Institution or Accountability? Exploring the Factors that Shape the Performance of National Human Rights Institutions and Equality Bodies', Policy and Politics 42, no. 1 (2014), 89-107.

${ }^{4}$ Smith, The Unique Position of NHRIs.

${ }^{5}$ Spencer and Harvey, Context, Institution or Accountability?

${ }^{6}$ A parliamentary committee whose membership is drawn from both the House of Commons and the House of Lords

${ }^{7}$ Office of the High Commissioner for Human Rights [OHCHR], National Human Rights Institutions: History, Principles, Roles and Responsibilities (New York and Geneva: United Nations, 2010).

${ }^{8}$ Kumar, National Human Rights Institutions.

${ }^{9} \mathrm{OHCHR}$, National Human Rights Institutions.

${ }^{10}$ Sonia Cardenas, 'Adaptive States: The Proliferation of National Human Rights Institiutions', Carr Centre for Human Rights Working Paper T-01-04 (2001); Tom Pegram, 'Diffusion Across Political Systems: The Global Spread of National Human Rights Institutions', Human Rights Quarterly 32, no. 3 (2010): 729-60.

${ }^{11}$ Sonia Cardenas, 'Emerging Global Actors: The United Nations and National Human Rights Institutions'. Global Governance 9, no.1 (2003): 23-42.

12 Rajeev Syal and David Hencke, 'Budget Cuts Could Downgrade UK Rights Watchdog's UN Status', Guardian (October 26 2012) http://www.theguardian.com/society/2012/oct/26/budget-cuts-rights-watchdog-un-status (accessed 24/6/15).

${ }^{13}$ Emma Gilligan, 'The Human Rights Ombudsman in Russia: The Evolution of Horizontal Accountability', Human Rights Quarterly 32, no.3 (2010): 575-600; Chidi Odinkalu, 'From Architecture to Geometry: The Relationship Between the African Commission on Human and Peoples' Rights and Organs of the African Union', Human Rights Quarterly 35, no.4 (2013): 850-869; John D. Ciorciari, 'Institutionalising Human Rights in Southeast Asia', Human Rights Quarterly 34, 3 (2012): 695-725; Andrew Wolman, 'The Relationship Between National and Sub-National Human Rights Institutions in Federal States', International Journal of Human Rights 17, no.4 (2013): 445-462.

${ }^{14}$ Smith, The Unique Position of National Human Rights Institutions; Spencer and Harvey, Context, Institution or Accountability?

15 United Nations [UN] Charter of the United Nations: Article 1 (1945).

${ }^{16}$ Christopher Pollitt and Colin Talbot, Unbundled Government: A Critical Analysis of the Global Trend to Agencies, Quangos and Contractualisation (London: Routledge, 2004).

${ }^{17}$ Sandra van Thiel and Zetter van der Wal, 'Birds of a Feather? The Effect of Organisational Value Congruence on the Relationship Between Ministries and Quangos', Public Organisation review 10 (2010): 377-397.

${ }^{18}$ Catherine Durose, Jonathan Justice and Chris Skelcher, 'Governing at Arm's Length: Eroding or Enhancing Democracy?' Policy and Politics 43, no.1 (2015), 137-153.

${ }^{19}$ Katherine Tonkiss and Chris Skelcher, 'The Discursive Construction of Institutional Reform: The Case of the Audit Commission', Local Government Studies (2015); Amanda Smullen, 'Translating Agency Reform (Basingstoke: Palgrave Macmillan, 2010).

${ }^{20}$ Spencer and Harvey, Context, Institution or Accountability?

${ }^{21}$ Sarah Spencer, 'Equality and Human Rights Commission: A Decade in the Making', Political Quarterly 79, no. 1 (2008): 6-16. 
${ }^{22}$ Directive 2000/43/EC of the European Council of $29^{\text {th }}$ June 2000; Directive 2000/78/EC of the European Council of $27^{\text {th }}$ November 2000.

${ }^{23}$ Tufyal Choudhury, 'The Commission for Equality and Human Rights: Designing the Big Tent', Maastricht J. Eur. \& Comp. L. 13, no.3 (2006): 311-322; Spencer, Equality and Human Rights Commission.

${ }^{24}$ Joint Committee on Human Rights [JCHR], 'The Case for a Human Rights Commission' (London: TSO, 2003).

${ }^{25}$ Subsequent research has challenged the extent to which combining regulatory functions with equality promotion functions is desirable on the basis that it created tensions in the first years that the institution was active. See Deborah Mabbett, 'Aspirational Legalism and the Role of the Equality and Human Rights Commission in Equality Policy', Political Quarterly 79, no.1 (2008): 45-52; Bob Niven, 'The EHRC: Transformational, Progressively Incremental or a Disappointment?', Political Quarterly 79, no.1 (2008): 17-26. ${ }^{26}$ OHCHR, National Human Rights Institutions.

${ }^{27} \mathrm{JCHR}$, The Case for a Human Rights Commission.

${ }^{28}$ JCHR, The Case for a Human Rights Commission; Niven, The EHRC; Cole O'Cinneide, 'The Commission for Equality and Human Rights: A New Institution for New and Uncertain Times', Industrial Law Journal 36, no.2 (2007): 141-162.

${ }^{29}$ Equality Act, 2006, c.3, 2.

${ }^{30} \mathrm{JCHR}$, 'Commission for Equality and Human Rights: The Government's White Paper' (London: TSO, 2004).

${ }^{31}$ See also Choudhury, The Commission for Equality and Human Rights.

${ }^{32}$ Colin Harvey and Sarah Spencer, 'Advancing Human Rights and Equality: Assessing the Role of the Commissions in the United Kingdom and Ireland', Fordham International Law Review 35, no.6 (2011): 1615-89.

${ }^{33}$ Equalities and Human Rights Commission [EHRC], 'How Fair is Britain? Equality, Good Relations and Human Rights in 2010' (2010) http://www.equalityhumanrights.com/about-us/our-work/key-projects/how-fairbritain/full-report-and-evidence-downloads (accessed 24/6/15).

${ }^{34}$ EHRC, The Equality and Human Rights Commission's Response to the Government: Consultation Paper: 'Building a Fairer Britain' (2010) http://www.equalityhumanrights.com/about-us/about-the-commission/ourvision-and-mission/government-consultation-on-our-future (accessed 24/6/15).

35 In 2012, GEO moved again to the Department for Culture, Media and Sport and the EHRC again moved with it

${ }^{36}$ Public Accounts Committee, 'Equality and Human Rights Commission' (London: TSO, 2010).

${ }^{37}$ JCHR, 'Equality and Human Rights Commission' (London, TSO: 2010).

38 JCHR ibid. 3.

39 JCHR ibid. 14.

${ }^{40}$ Interview 3

${ }^{41}$ Interview 1.

${ }^{42}$ Cabinet Office, 'Public Bodies 2014' https://www.gov.uk/government/publications/public-bodies-2014 (accessed 14/6/15).

${ }^{43}$ Theresa May Letter to Dr. Hywel Francis MP JCHR (March 21 2011)

http://www.parliament.uk/documents/ioint-committees/humanrights/Letter from Theresa May on Future shape of EHRC.pdf, 1 (accessed 24/6/15).

${ }^{44}$ Katharine Dommett, Matthew Flinders, Chris Skelcher and Katherine Tonkiss 'Did they Read Before Burning? The Coalition and Quangos', Political Quarterly 85 (2014): 133.

${ }^{45}$ May, Letter to Dr. Hywel Francis.

${ }^{46}$ Government Equalities Office GEO Impact Assessment: Reform of the Equalities and Human Rights Commission (2012)

https://www.gov.uk/government/uploads/system/uploads/attachment data/file/85309/GEO-impactassessment.pdf (accessed 24/6/15).

${ }^{47}$ HC Deb $7^{\text {th }}$ March 2011, vol. 389, col 1491.

${ }^{48}$ Interview 2.

${ }^{49}$ EHRC, How Fair Is Britain?

${ }^{50}$ Daily Mail, 'These Human Rights rulings are Bonkers... And That's From the Equalities Chief!' Daily Mail (December 12 2011) http://www.dailymail.co.uk/news/article-2072835/Human-rights-rulings-bonkers-saysEHRC-chief-Trevor-Phillips.html; Daily Mail Political Correctness Continues to Stifle Debate on Multiculturalism Daily Mail (October 4 2011) http://www.dailymail.co.uk/debate/article-2044748/Political-correctnesscontinues-stifle-debate-regarding-impact-multiculturalism.html. (accessed 24/6/15).

${ }^{51}$ EHRC Human Rights Review (2012) http://www.equalityhumanrights.com/about-us/our-work/humanrights/human-rights-review; Spencer, Equality and Human Rights Commission. 
${ }^{52}$ Analysis conducted via www.theyworkforyou.com

${ }^{53}$ Joint Committee of Human Rights (2010) Allegation of Contempt: Mr. Trevor Phillips. London: The Stationery Office. The Committee ultimately did not uphold the complaint, but did not that some of the chair's actions could be seen as inappropriate communication.

${ }^{54}$ Conservative Party (2010) Invitation to Join the Government of Britain [online]

https://www.conservatives.com/ /media/files/activist\%20centre/press\%20and\%20policy/manifestos/manifes to2010 (accessed 23/9/15).

${ }^{55}$ BBC News, 'Coalition Slowing Human Rights Reform, Says Cameron' (March 14 2012)

http://www.bbc.co.uk/news/uk-politics-17361162 (accessed 24/6/15). Although, the Government's plan to abolish the Human Rights Act is expected to struggle to be passed as a law, and is subject to delay. See Wintour, P. (2015) Cameron set to delay plans to scrap Human Rights Act. The Guardian [online] http://www.theguardian.com/law/2015/may/27/david-cameron-delay-scrap-human-rights-act-queen-speech (accessed 23/9/15).

${ }^{56}$ Joanna Dawson The Human Rights Act: Proposals for Reform House of Commons Library Standard Note SN/HA/6825 (2014).

57 Interview 1.

58 Interview 1.

${ }^{59}$ HM Government 'Building a Fairer Britain: Reform of the Equality and Human Rights Commission: Response to the Consultation' (2012) https://www.gov.uk/government/publications/response-to-the-consultationbuilding-a-fairer-britain-reform-of-the-equality-and-human-rights-commission (accessed 24/6/15).

${ }^{60} \mathrm{EHRC}$, consultation response.

${ }^{61} \mathrm{Ibid} .8$

${ }^{62} \mathrm{HM}$ Government, Building a Fairer Britain, 3-4.

$63 \mathrm{lbid}$.

${ }^{64}$ This ultimately involved a $68 \%$ budget cut and $66 \%$ staffing cut, which trade unions argued against on the basis that it meant 'the closure of the EHRC as we know it and its transformation into little more than a thinktank. Source: PCS. What price equality? The impact of the proposed cuts and members' vision for the future of the Equality and Human Rights Commission (leaflet on file with author).

${ }^{65}$ See Kingdon on policy windows: John Kingdon, 'Agendas, Alternatives and Public Policies' (Boston, Little, Brown \& Co: 1984).

${ }^{66}$ Interview 4.

${ }^{67}$ Interview 4.

68 Interview 1.

${ }^{69}$ Department for Culture, Media and Sport Department for Culture, Media and Sport and the Equality and Human Rights Commission: Framework Document (2013)

http://www.equalityhumanrights.com/sites/default/files/documents/aboutus/dcms ehrc framework docum ent 2013.pdf (accessed 24/6/15).

${ }^{70}$ Cabinet Office Cabinet Office Controls Guidance, Version 3.2 (2014)

https://www.gov.uk/government/publications/cabinet-office-controls/cabinet-office-controls-guidanceversion-32 (accessed 24/6/15).

${ }^{71}$ EHRC Close to Home: An Inquiry into Older People and Human Rights in Care Homes (2011)

http://www.equalityhumanrights.com/publication/close-home-inquiry-older-people-and-human-rights-homecare (accessed 24/6/15).

${ }^{72}$ EHRC Your Home Care and Human Rights (2012)

http://www.equalityhumanrights.com/sites/default/files/documents/legal/your home_care... a5 40pp book let web aw.pdf (accessed 24/6/15).

73 Interview 1.

74 Interview 2.

75 Interview 4.

${ }^{76}$ EHRC Deregulation Bill (2014)

http://www.equalityhumanrights.com/sites/default/files/uploads/documents/Parli Briefings/deregulation bil I second reading brefing final.doc (accessed 24/6/15).

$77 \mathrm{HL}$ Deb $20^{\text {th }}$ November 2014, col. GC229.

${ }^{78}$ EHRC Enterprise and Regulatory Reform Bill (2012) http://www.equalityhumanrights.com/legal-andpolicy/our-legal-work/parliamentary-briefings/enterprise-and-regulatory-reform-bill-2012-13 (accessed 24/6/15). 
79 lbid. 25.

${ }^{80}$ OHCHR Paris Principles: 20 Years Guiding the Work of National Human Rights Institutions (2013) http://www.ohchr.org/EN/NewsEvents/Pages/ParisPrinciples20yearsguidingtheworkofNHRI.aspx (accessed 24/6/15).

81 Interview 1.

82 Goodman, R. and Pegram, T. (2012) 'Introduction: National Human Rights Institutions, State Conformity and Social Change', in Goodman, R. and Pegram, T. (eds.) National Human Rights Institutions, State Conformity and Social Change. Cambridge: Cambridge University Press. 